\title{
1 Deciphering the molecular mechanism of stop codon readthrough
}

3 Martine Palma and Fabrice Lejeune*

Univ. Lille, CNRS, Inserm, CHU Lille, Institut Pasteur de Lille, UMR9020 - UMR 1277 -

CANTHER - Cancer Heterogeneity, Plasticity and Resistance to Therapies, F-59000 Lille,

6 France

7

8

9 10

*Author for correspondence (E-mail: fabric.lejeune@inserm.fr; Tel.: 33-320871059 ).

\section{ABSTRACT}

Recognition of the stop codon by the translation machinery is essential to terminating translation at the right position and to synthesizing a protein of the correct size. Under certain conditions, the stop codon can be recognized as a coding codon promoting translation, which then terminates at a later stop codon. This event, called stop codon readthrough, occurs either by error, due to a dedicated regulatory environment leading to generation of different protein isoforms, or through the action of a readthrough compound. This review focuses on the mechanisms of stop codon readthrough, the nucleotide and protein environments that facilitate or inhibit it, and the therapeutic interest of stop codon readthrough in the treatment of genetic diseases caused by nonsense mutations.

Key words: stop codon readthrough, mechanism, translation termination, premature termination codon, readthrough activators, molecules, screening.

\section{CONTENTS}


I. Introduction

II. Translation termination

III. Different types of stop codon readthrough

(1) Non-programmed translational readthrough

(2) Programmed translational readthrough

(3) Induced translational readthrough

IV. Parameters influencing stop codon readthrough

(1) Cis elements activating stop codon readthrough

(2) Trans elements activating readthrough

(a) Proteins and RNAs

(i) Factors involved in the general process of stop codon readthrough

(ii) Factors involved in specific stop codon readthrough events

(b) Small molecules

(c) Cell environment

V. Therapeutic interest of stop codon readthrough

VI. New developments and therapeutic targets

VII. Conclusions

VIII. Acknowledgements

IX. References

\section{INTRODUCTION}

For cells to function properly, genetic information must be faithfully expressed in RNAs or proteins. A key step in the gene expression pathway is translation from messenger RNA (mRNA) to protein. Translation obeys very specific rules, such as starting at an initiation codon (very often an AUG codon) and stopping at one of the three stop codons UAA, UAG, 
or UGA, in order to ensure accurate protein length. Sometimes, however, rules can be bypassed, and translation is no exception. Under specific conditions, ribosomes may ignore stop codons, continuing with translation and extending the C-terminal part of the nascent protein. The C-terminally extended protein may acquire a new functional domain in this way. The absence of termination codon recognition is called stop codon readthrough. Although this can constitute a decoding error, stop codon readthrough can also be a means of expressing different protein isoforms and may represent a therapeutic solution for some pathologies. This review discusses the different molecular factors that regulate translation termination and stop codon readthrough, mainly in higher eukaryotes. It also outlines the potential of this mechanism in terms of basic science and clinical applications to advance understanding of pathways of gene expression and in the development of therapeutic approaches for nonsensemutation-related genetic diseases. Potential clinical applications of a stop codon readthrough strategy have recently been discussed in several reviews (Morais, Adachi \& Yu, 2020; Dabrowski, Bukowy-Bieryllo \& Zietkiewicz, 2018; Sharma, Keeling \& Rowe, 2020; Bezzerri et al., 2020), hence we focus here on the molecular mechanisms leading to stop codon readthrough.

\section{TRANSLATION TERMINATION}

Translation is a process that promotes amino acid polymerization leading to a peptide sequence based on an mRNA sequence. The ribosome carries out translation with the help of cofactors, ensuring accurate decoding of the open reading frame (ORF) (Dever, Kinzy \& Pavitt, 2016; Merrick, 1992; Kapur, Monaghan \& Ackerman, 2017). Misincorporation of an amino acid occurs at a very low rate. For example, misincorporation of a lysine instead of an arginine during translation of protamine mRNA has been estimated at only $0.06 \%$ to $0.2 \%$ (Mori et al., 1985). Site A of the ribosome is where the transfer RNA (tRNA) carrying an 
amino acid hybridizes with a codon via its anticodon sequence, thus bringing to the growing polypeptide chain the next amino acid to be incorporated (Fig. 1A). tRNAs are subject to numerous post-transcriptional modifications that stabilize their tertiary and quaternary structures and also favour codon-anticodon interaction in the ribosome by changing the polarity of the modified base and allowing additional interactions with the ribosome (Grosjean \& Westhof, 2016). It is established that post-transcriptional modifications of tRNAs play a role in the fidelity of codon recognition, and their absence can lead to increased codon recognition by near-cognate tRNAs (Blanchet et al., 2018).

Translation termination occurs when site A of the ribosome reaches one of three stop codons (UAA, UAG or UGA) in frame with the translation initiation codon (Fig. 1A). In human cells, the only tRNA to recognize these stop codons is tRNA ${ }^{[\mathrm{Ser}] \mathrm{Sec}}$, which carries the amino acid selenocysteine and pairs with UGA stop codons in a dedicated environment such as a selenocysteine insertion sequence (SECIS) combined with the presence of SECIS bindingprotein 2 (SBP2) (Labunskyy, Hatfield \& Gladyshev, 2014). When the ribosome reaches a stop codon, competition occurs between the translation termination complex and near-cognate tRNAs recognizing two of the three bases constituting the stop codon. Likely because of a lower energetic stability of stop codon recognition by a near-cognate tRNA, the translation termination complex is recruited in more than $99.9 \%$ of cases (Floquet et al., 2012; Rajon \& Masel, 2011). UAG and UAA stop codons share the same near-cognate tRNAs, which differ from those recognizing UGA stop codons. The amino acids glutamine, tyrosine, and lysine are incorporated during UAG or UAA readthrough, whereas arginine, cysteine, and tryptophan can be incorporated during UGA readthrough, consistent with their positions in the genetic code table (Feng et al., 1990; Roy et al., 2015). Yet our understanding of stop codon misdecoding by near-cognate tRNAs is far from complete, since other amino acids have also been found to be incorporated during readthrough, according to the nonsense mutation and its 
nucleotide context. In particular, leucine is the main amino acid incorporated during readthrough of the UGA nonsense mutation at position 1282 (mutation $\mathrm{W} 1282 \mathrm{X}$ ) of the cystic fibrosis transmembrane conductance regulator (CFTR) gene (Xue et al., 2017). It is important to note that the protein synthesized may or may not be functional according to the amino acid incorporated at the site of the nonsense mutation, if this position is crucial for the function or stability of the protein.

The translation termination complex is composed of at least two subunits, called eukaryotic release factors (eRFs) 1 and 3 (Fig. 1A). The eRF1 subunit mimics a tRNA and enters the A site of the ribosome to recognize the stop codon (Muramatsu et al., 2001; Song et al., 2000). In eukaryotic cells, interestingly, eRF1 recognizes all three stop codons, whereas in prokaryotic cells, two release factors (RFs) are necessary: RF-1 recognizes UAA and UAG stop codons, whereas RF-2 recognizes UAA and UGA stop codons. To understand how eRF1 recognizes all three stop codons, Brown et al. (2015) used cryo-electron microscopy and a catalytically inactive eRF1 to show that glutamic acid at position 55 and tyrosine at position 125 of eRF1 discriminate between purines and pyrimidines at the second and third base positions of a codon. They thus play a crucial role in the ability of eRF1 to recognize stop codons (Brown et al., 2015). The eRF3 subunit is a GTPase whose activity is stimulated mainly by interaction with either the polyA-binding protein (PABP), when translation termination occurs at the physiological stop codon, or the nonsense-mediated mRNA decay (NMD) factor UPF3X (also called UPF3B), when translation termination occurs at a premature termination codon (PTC) (Neu-Yilik et al., 2017). When eRF3 catalyses conversion of GTP to GDP, it induces a conformational change in the structure of eRF1, promoting translation termination through release of the nascent peptide chain and replacement of eRF3 by the ATPase ABCE1 (ATP Binding Cassette Subfamily E Member 1). ABCE1 will then hydrolyse ATP to ADP to promote recycling of the two ribosomal subunits 
(Fig. 1A). In addition to the stop codon and to certain proteins located downstream of the stop codon (PABP or UPF3X for instance), the nucleotide environment around the stop codon, and particularly certain post-transcriptional modifications, may influence the translation termination process. A transcriptome-wide mRNA methylation analysis has revealed a high level of methylation at position 6 of adenosine (m6A) at the end of the ORF and the beginning of the 3' untranslated region (UTR), in the vicinity of the stop codon. This deserves further investigation and clarification, as it suggests a possible role of this mark in translation termination (Meyer et al., 2012; Li et al., 2014).

\section{DIFFERENT TYPES OF STOP CODON READTHROUGH}

Although translation termination must be a very efficient process to ensure the correct protein size, under certain conditions or at a very low rate, a near-cognate tRNA can be recruited to the A site of the ribosome when the latter reaches a stop codon. The consequence of this is that translation continues until a later stop codon that promotes translation termination. This event is called stop codon readthrough (Fig. 1B). Several types of readthrough can occur at stop codons, depending on the presence of regulatory elements or of readthrough-promoting molecules (Fig. 2).

\section{(1) Non-programmed translational readthrough}

In the absence of any readthrough molecules, readthrough of any physiological stop codon or PTC can occur at a basal level. This readthrough can be considered a translation error and is referred to here as non-programmed translational readthrough (Fig. 2A). This type of readthrough is a rare event, calculated as less than $0.1 \%$ in more than $80 \%$ of cases (Rajon \& Masel, 2011; Floquet et al., 2012; Fearon et al., 1994). Interestingly, the likelihood of nonprogrammed translational readthrough depends on the identity of the stop codon. It is highest 
at the UGA stop codon, whereas translation termination is most efficient at the UAA stop codon. In the case of PTCs, this very low readthrough rate is partly due to competition between near-cognate tRNAs and release factors, in favour of the former, but it is also due in part to activation of the surveillance mechanism provided by NMD, which results in silencing of the gene (Gupta \& Li, 2018; Lejeune, 2017; Kurosaki \& Maquat, 2016; He \& Jacobson, 2015). Non-programmed translational readthrough thus occurs on the fraction of PTCcarrying mRNAs that escape NMD (Kuzmiak \& Maquat, 2006).

Although the amount of protein generated by non-programmed translational readthrough is minute compared to the amount of protein produced without readthrough of a physiological stop codon or from the wild-type mRNA in the case of a PTC, the consequences of nonprogrammed translational readthrough can be considerable. For example, the phenotypes of patients suffering from the same pathology and carrying the same nonsense mutation may vary even though they should be identical due to silencing of the mutant gene. Some cystic fibrosis patients with a nonsense mutation that one would assume to cause a severe phenotype due to the absence of the CFTR protein actually show mild pulmonary damage (Cutting et al., 1990; Kerem et al., 1990). The level of non-programmed translational readthrough has been proposed to explain this mild phenotype, allowing some functional full-length CFTR protein to be synthesized.

\section{(2) Programmed translational readthrough}

The second type of readthrough is called programmed translational readthrough (Fig. 2B). It targets specific mRNAs (Loughran et al., 2018; Freitag, Ast \& Bolker, 2012; Dunn et al., 2013) and is a proteome-expanding mechanism allowing synthesis of specific protein isoforms with particular functions. It is thus a way to synthesize two isoforms of a protein from one mRNA. A specific regulatory mechanism intervenes at the physiological stop codon 
either to terminate translation at the first stop codon in phase with the initiation codon starting the ORF or to promote its readthrough so as to terminate translation at one of the downstream stop codons in phase with the initiation codon. This type of readthrough has been identified in viruses, fungi, Drosophila spp., and mammals. In human cells, programmed translational readthrough is thought to be a very rare event, reported to affect the expression of only a dozen genes: the opioid receptor Kappa 1 (OPRK1), opioid related nociceptin receptor 1 (OPRL1), aquaporin 4 (AQP4), mitogen-activated protein kinase 10 (MAPK10), peroxisomal lactate dehydrogenase B (LDHB), malate dehydrogenase (MDH1), vitamin D receptor (VDR), vascular endothelial growth factor A (VEGFA), myelin protein zero (MPZ), and beta-globin genes (Loughran et al., 2014, 2018; Chittum et al., 1998; Yamaguchi et al., 2012; Eswarappa et al., 2014; Schueren et al., 2014; Geller \& Rich, 1980). It appears more frequent in other species. In Drosophila melanogaster, for example, the expression of several hundred genes is regulated via this readthrough process (Lin et al., 2007). Similarly, some $5 \%$ of yeast genes appear to be subject to programmed translational readthrough (Kleppe \& Bornberg-Bauer, 2018). An in silico analysis aiming to identify physiological stop codons putatively subject to programmed translational readthrough suggests that this process may actually occur more frequently than previously thought in many species, including humans (Jungreis et al., 2016; Dunn et al., 2013). Consistent with these results, ribosome profiling performed on human foreskin fibroblasts revealed 42 genes as potentially subject to programmed translational readthrough. Interestingly, this process has been shown to generate C-terminally extended proteins very efficiently, with the amount of protein formed exceeding the amount of unextended product protein by up to 30\% (Loughran et al., 2014; Singh et al., 2019). This suggests that specific translation termination regulation occurs at these physiological stop codons and that cis elements and trans-acting factors must be involved in promoting an 
exceptionally high rate of readthrough. Some such elements have been identified and are described in Section IV.

\section{(3) Induced translational readthrough}

The third type of stop codon readthrough is PTC readthrough promoted by certain molecules (Fig. 2C), here termed induced stop codon readthrough. When the ribosome reaches a stop codon, the presence of such molecules favour recruitment of near-cognate tRNAs instead of the translation termination complex. In early studies, aminoglycosides were shown to facilitate this type of readthrough process in bacteria and yeast (Singh, Ursic \& Davies, 1979).

The first evidence of induced nonsense mutation readthrough in mammalian cells was reported a few years later in a study of G418 and paromomycin aminoglycosides (Burke \& Mogg, 1985). Since then, both aminoglycoside and non-aminoglycoside molecules have been identified as readthrough molecules (see Section IV) that might potentially be used to treat nonsense-mutation-related pathologies.

Several lines of evidence indicate that induced translational readthrough occurs at PTCs and not at physiological stop codons. The nucleotide and protein environments around physiological stop codons have been evolutionarily selected to facilitate translation termination. This is not true of PTCs, since they appear through mutation in an environment selected to promote translation and not translation termination. While PTCs do promote translation termination, they are more sensitive to readthrough than physiological stop codons. Although several studies using readthrough molecules have shown the absence of readthrough at physiological stop codons (Benhabiles et al., 2017; Trzaska et al., 2020; Welch et al., 2007), it remains necessary to demonstrate for each new molecule that it does not impact translation termination at physiological stop codons. 
Interestingly, the efficiency of translational readthrough induced by a molecule may be related to the level of non-programmed translational readthrough (basal level of readthrough) occurring at the stop codon in the absence of that molecule: the higher the level of basal readthrough, the more efficient the readthrough promoted by molecules such as aminoglycosides (Floquet et al., 2012), which should be taken into account when implementing a therapeutic approach for a given nonsense mutation.

\section{PARAMETERS INFLUENCING STOP CODON READTHROUGH}

The basal readthrough level varies from one stop codon to another, as shown in various studies (Fearon et al., 1994; Floquet et al., 2012; Rajon \& Masel, 2011). The identity of the stop codon influences this level, but other elements acting in cis or trans can also modulate the efficiency of PTC or physiological stop codon readthrough. Such elements can influence all three types of stop codon readthrough.

\section{(1) Cis elements activating stop codon readthrough}

Stop codon readthrough efficiency can be influenced by various factors, including the identity of the stop codon and the nucleotide sequence surrounding it (Bidou et al., 2004; Howard et al., 2000). Results from studies where a PTC was introduced into a reporter gene show that the UGA stop codon is the most permissive to readthrough and the UAA stop codon is the least permissive (Bidou et al., 2004; Floquet et al., 2012; Howard et al., 2000; Wangen \& Green, 2020; Manuvakhova, Keeling \& Bedwell, 2000). However, these properties can be altered by the nucleotide context of the stop codon (Bonetti et al., 1995; McCaughan et al., 1995; Cassan \& Rousset, 2001). In particular, counting the first nucleotide of the stop codon as position +1 , the nucleotide at position +4 strongly influences translation termination efficiency. It appears that a purine at this position, as found in about $90 \%$ of the most highly 
expressed human genes, favours translation termination (Tate \& Mannering, 1996), whereas a pyrimidine facilitates readthrough (Brown et al., 1990; McCaughan et al., 1995; Tate \& Mannering, 1996). In particular, the presence of a cytosine at position +4 has been shown to allow, in most cases, the most efficient stop codon suppression (Floquet et al., 2012; Howard et al., 2000; Phillips-Jones, Watson \& Martin, 1993; Wangen \& Green, 2020), although this is not an absolute rule. The nucleotide environment most favourable to efficient readthrough also depends on the identity of the stop codon. Manuvakhova et al. (2000) found cytosine to be the most favourable nucleotide at position +4 for promoting readthrough of UGA and UAA stop codons, but readthrough of UAG stop codons was most efficient when the other pyrimidine, uracil, is present at that position.

The nucleotide immediately following the stop codon is not the only nucleotide that can influence readthrough efficiency. Several studies have demonstrated that some downstream nucleotides can favour readthrough. Recently, a study measuring stop codon readthrough by ribosome profiling showed that the two nucleotides immediately downstream of the stop codon strongly influence readthrough efficiency (Wangen \& Green, 2020). The authors concluded that enrichment in adenosines or uridines in the vicinity of the stop codon favours stop codon readthrough, whereas enrichment in guanosines or cytosines favours translation termination. Other studies have demonstrated that both upstream and downstream sequences influence the readthrough rate at a stop codon. In particular, CAA sequences upstream and downstream of a UAG stop codon in the ste6 gene in yeast or in a reporter gene have been shown to act synergistically to promote readthrough (Fearon et al., 1994; Manuvakhova et al., 2000; Bonetti et al., 1995; Xue et al., 2014).

According to the reporter system used to investigate readthrough efficiency, the upstream and downstream consensus sequences favouring stop codon readthrough may differ slightly. For example, the downstream sequences CAR YYA (where $\mathrm{R}$ is a purine and $\mathrm{Y}$ is a pyrimidine) 
and CAR NBA (where $\mathrm{N}$ is any of the four nucleotides and $\mathrm{B}$ can be $\mathrm{U}, \mathrm{C}$ or $\mathrm{G}$ ) seem to favour stop codon readthrough (Namy, Hatin \& Rousset, 2001; Harrell, Melcher \& Atkins, 2002; Beier \& Grimm, 2001). These hexanucleotide sequences are found in several virus and cell genes associated with the regulation of programmed translational readthrough (Skuzeski et al., 1991). The upstream sequence can also affect readthrough efficiency. For example, one study found that the nucleotide sequence spanning positions -6 to +9 influences readthrough rate. In particular, positions -1 and +4 were crucial for readthrough activation, and the sequence U STOP C has been reported as the consensus sequence for efficient readthrough (Floquet et al., 2012). Supporting the idea of involvement of the upstream sequence in promoting readthrough, a recent study on the glycosyltransferase gene B4GALNT1 has demonstrated that the base triplet AGC, immediately upstream and downstream of the PTC, is required for efficient basal readthrough generated by the M4 nonsense mutation at amino acid 228 (Yesmin et al., 2020). Overall, all these studies indicate that stop codon readthrough efficiency is modulated by cis elements that have not yet been clearly identified and that are likely to differ among genes. It remains very difficult to predict with certainty the rate of readthrough of a stop codon without additional experimental data. For instance, when attempting to explain why a given readthrough molecule has variable effects on the same nonsense mutation located at different positions in a gene, one must consider the influence of the stop-codon-surrounding sequence on readthrough efficiency. This is especially true when the goal is to develop a therapeutic approach (Martorell et al., 2020).

Besides the immediate primary sequence surrounding the stop codon, some secondary structures have been shown to facilitate stop codon readthrough. In the Moloney murine leukemia virus, a pseudoknot located eight nucleotides downstream of the stop codon separating the gag and pol ORFs promotes readthrough by about $5 \%$ of the ribosomes reaching this stop codon (Wills, Gesteland \& Atkins, 1991). Since this discovery, efficient 
readthroughs have been found to require other secondary structures (e.g. conserved hairpins) occurring at stop codons from various virus genomes (Firth et al., 2011). The exact mechanism remains obscure, but these results suggest that certain proteins could be recruited by these secondary structures to promote readthrough.

\section{(2) Trans elements activating readthrough}

When the ribosome reaches a stop codon, it must terminate translation or ignore this translation termination signal by incorporating an amino acid and continuing translation of the ORF to a downstream stop codon. To understand the mechanisms underlying the 'decision' to stop translation or to continue, specific factors dedicated to stop codon readthrough have been sought. Some endogenous trans elements have been identified as proteins or RNAs required either for readthrough of specific stop codons or for the general readthrough mechanism.

Molecules with the capacity to promote readthrough are of particular interest because of their potential in treating nonsense-mutation-related pathologies. Finally, the cell environment has been shown to influence readthrough efficiency, suggesting that regulation of the readthrough process may occur according to culture conditions.

\section{(a) Proteins and RNAs}

To date, only a few factors have been implicated in the readthrough process, some affecting all stop codon readthroughs and some that are specific to readthrough of one particular stop codon.

\section{(i) Factors involved in the general process of stop codon readthrough}

As readthrough opposes translation termination and vice versa, it is not surprising that loss of function of proteins involved in translation termination leads to increased levels of stop codon 
readthrough. For example, the proteins termination and polyadenylation 1 (TPA1) and Ccr4 associated factor 1 (CAF1 also called POP2) involved in regulating the length of the poly(A) tail also participate in the translation termination process. In experiments using the firefly luciferase reporter gene carrying a PTC, loss of TPA1 or POP2 function in yeast resulted in increased basal readthrough levels (Keeling et al., 2006). These proteins can thus be viewed as inhibitors of stop codon readthrough. However, in both yeast and human cells, the nucleotide context appears to determine whether TPA1 exerts a positive or a negative influence on stop codon readthrough (Loenarz et al., 2014). In yeast, the balance between translation termination efficiency and stop codon readthrough efficiency can be altered by the expression levels of the inhibitor of translation termination 1 (ITT1) gene. This was demonstrated in experiments using a PGK1-STOP-LacZ reporter construct, in which overexpression of ITT1 caused increased basal levels of readthrough (Urakov et al., 2001). Another example of the antagonism between translation termination efficiency and stop codon readthrough activation is illustrated by the dead-box RNA helicase Dbp5/DDX19, which is involved in translation termination. Dbp5/DDX19 interacts with eRF1, bringing it into contact with eRF3 so as to promote translation termination (Fig. 1). If the function of Dbp5/DDX19 is impaired, eRF1 interacts prematurely with eRF3 leading to failure of the translation termination process, thus allowing near-cognate tRNAs to enter the A site of the ribosome, recognize the stop codon, and promote readthrough (Gross et al., 2007; Mikhailova et al., 2017; Beissel et al., 2019).

Although it makes sense that proteins involved in the translation termination process can interfere with stop codon readthrough, it is surprising to note the presence of translation initiation factors among the proteins that modulate stop codon readthrough. In both yeast and human cells, the eukaryotic initiation translation factor 3 (eIF3) seems to play a general role in programmed translational readthrough. The absence of functional eIF3 reduces the basal 
level of readthrough of all three stop codons, provided they are in a readthrough-favourable nucleotide context (Beznoskova et al., 2015). To promote readthrough, eIF3 appears to act as an inhibitor of eRF1 by interacting with the pre-termination complex and interfering with pairing between eRF1 and the third base of the codon. By preventing recognition of the stop codon by eRF1, eIF3 favours recognition of the stop codon by a near-cognate tRNA, thus promoting stop codon readthrough.

It is also possible to modulate the efficiency of stop codon readthrough by acting on the fidelity of the translation process. tRNAs are subject to various post-transcriptional modifications that prevent erroneous codon recognition by the tRNA. For example, the wobble effect, proposed to explain recognition of the first two bases of a codon by a nearcognate tRNA independently of the third nucleotide (Crick, 1966), is strongly increased when these post-transcriptional modifications are not present (Duechler et al., 2016; Hagervall et al., 1990; Bednarova et al., 2017; Agris et al., 2017). Interestingly, the rules governing recognition of a stop codon by a near-cognate tRNA appear less restrictive than proposed by the wobble effect, as more tRNAs than expected can recognize a stop codon (Roy et al., 2015). Not only can codon recognition by a near-cognate tRNA occur via the first two bases of the codon independently of the third nucleotide, but it can also occur via the last two bases of the codon independently of the first. Similarly, the discovery that leucine is the amino acid most abundantly incorporated at the nonsense mutation W1282X in the CFTR gene suggests that a tRNA may recognize a stop codon with a mismatch at the central base of the triplet forming the codon (Xue et al., 2017).

Note also that, before being substrates of stop codon readthrough, PTC-carrying mRNAs are substrates of NMD. It is therefore tempting to connect these two mechanisms and to hypothesize that they share factors in common. In humans at least, this is indeed the case for some NMD factors: downregulation of the NMD factors Up frameshift (UPF) 1, 2, or 3X/3B 
impairs readthrough, indicating that these factors are necessary for this process (Jia et al., 2017; Ivanov et al., 2008). The exact roles of these NMD proteins in readthrough remain to be clarified, especially because contradictory reports have been published on this role of UPF proteins in other organisms such as yeast. It has notably been claimed that UPF proteins inhibit readthrough, since knockout of one UPF gene in yeast results in an increased readthrough rate (Salas-Marco \& Bedwell, 2005; Wang et al., 2001). However, another study failed to observe any effect of UPF gene knockout on the readthrough rate, suggesting that these proteins are not involved in readthrough (Harger \& Dinman, 2004). The role of the UPF proteins in stop codon readthrough thus may differ between yeast and humans. This warrants in-depth investigations into the connection between NMD and stop codon readthrough. Translation takes place a priori throughout the cytoplasm, and since stop codon readthrough shares the same translation machinery, it can be expected also to occur in the cytoplasm, without any dedicated sites. Yet a recent study demonstrated that the cytoskeleton influences PTC readthrough (Jia et al., 2017). In particular, basal readthrough is activated when formation of actin filaments is impaired. It thus seems that actin filaments are neither required for readthrough nor favourable to it, meaning that they may participate in some form of readthrough inhibition. The same study showed that non-programmed translational readthrough occurs at specific cytoplasmic foci different from P-bodies and named readthrough bodies (Jia et al., 2017). Their results suggest that PTC-containing mRNAs are actively targeted either to degradation by NMD or to undergo PTC readthrough. Although UPF proteins have been found in readthrough bodies (unlike the P-body marker decapping protein 1a (DCP1a), which is involved in NMD), readthrough body characterization remains poor and no specific proteins have been identified.

\section{(ii) Factors involved in specific stop codon readthrough events}


To explain programmed translational readthrough on an mRNA, cis elements have been identified (see Section IV.1). Often these cis elements work together with or recruit factors to promote readthrough of a specific stop codon. For example, heterogeneous nuclear ribonucleoprotein (hnRNP) A2/B1, an RNA-binding protein involved in primary microRNA (pri-miRNA) processing and in the trafficking and assembly of the human immunodeficiency virus (HIV) genome (Alarcon et al., 2015; Beriault et al., 2004; Levesque et al., 2006), is involved in programmed translational readthrough on VEGFA mRNA (Eswarappa et al., 2014; Houck-Loomis et al., 2011). HnRNP A2/B1 interacts with an A2 response element (A2RE) located downstream of the physiological stop codon to promote stop codon readthrough. Mutating the A2RE sequence or downregulating hnRNP A2/B1 impairs readthrough of the physiological stop codon of VEGFA mRNA. Whether hnRNP A2/B1 interacts with VEGFA pre-messenger RNA (pre-mRNA) or mRNA only has not yet been investigated, but given the nuclear localization of this protein, it could be an early mark for specific programmed translational readthrough.

More recently, Lethal 7a (Let7a) microRNA (miRNA) has been shown to promote programmed translational readthrough on Argonaute 1 (Ago1) mRNA, generating a longer isoform called Ago1x. The miRNA binds a sequence downstream of the physiological stop codon and upstream of the subsequent in-phase downstream stop codon. This sequence is sufficient to promote readthrough when introduced into a heterologous 3' UTR (Singh et al., 2019). This indicates that the mechanism is independent of the identity of the stop codon or of the mRNA, as long as a Let7a miRNA binding site is present downstream of the stop codon to be read through.

Both hnRNP A2/B1 and Let7a miRNA bind an RNA sequence located about 10 nucleotides downstream of the stop codon whose readthrough they promote. This suggests a possible interaction with the translation machinery pausing on the stop codon. In both cases, 
interestingly, the rate of translational readthrough of the canonical stop codon reaches at least 20\%, which can be considered very efficient stop codon readthrough (Eswarappa et al., 2014; Singh et al., 2019). Unfortunately, the precise mechanism remains to be determined in order to understand how these trans elements impair translation termination and efficiently promote synthesis of a C-terminally extended protein.

All factors involved in translation termination or stop codon readthrough constitute targets for the development of therapeutic approaches to treating genetic diseases caused by nonsense mutations. By inhibiting the synthesis of these factors or in some cases by overproducing them, stop codon readthrough is activated. Readthrough activation could thus represent a potential way to correct a nonsense mutation responsible for a pathology. Molecules capable of targeting the trans factors described in this section could be sought in the framework of developing a therapeutic approach. Yet to date, as discussed in Section V, this is not yet a common approach to identify readthrough molecules. The strategy used focuses on searching for molecules that target the readthrough mechanism as a whole, rather than targeting a specific factor.

\section{(b) Small molecules}

Because of their potential therapeutic interest, molecules activating PTC readthrough have been the focus of many studies. Historically, some members of the aminoglycoside family have shown the capacity to promote PTC readthrough (Burke \& Mogg, 1985). This family of molecules is composed of a sugar substituted with one amino group. However, not all members of this family promote significant stop codon readthrough: gentamicin, geneticin (G418), paromomycin, neomycin, and lividomycin do have this effect (Table 1), but hygromycin, streptomycin, kanamycin, tobramycin, and amikacin do not (Manuvakhova et al., 2000). Aminoglycosides promote stop codon readthrough by interacting with the $16 \mathrm{~S}$ 
ribosomal RNA located in the decoding centre of the ribosome (Carter et al., 2000; Ogle, Carter \& Ramakrishnan, 2003; Prokhorova et al., 2017; Zingman et al., 2007). Besides aminoglycosides, several non-aminoglycoside molecules have also been shown to promote PTC readthrough (Table 2). PTC124/ataluren/translarna, an oxadiazole derivative, is the only molecule to have reached clinical phase II/III trials for the treatment of genetic diseases caused by nonsense mutations (Welch et al., 2007; Kerem et al., 2014). This molecule, which can rescue expression of genes carrying UGA, UAG, or UAA nonsense mutations, has a mode of action that remains to be clarified, but might either target the A site of the ribosome as do aminoglycosides or interact directly with the stop codon to promote readthrough (Roy et al., 2016; Tutone et al., 2019). Even though the efficacy of this molecule seems too low for clinical development aimed at treating, for example, cystic fibrosis or Duchenne muscular dystrophy (Haas et al., 2015; Kerem et al., 2014), it does illustrate the need to identify readthrough molecules that might enhance the treatment of nonsense-mutation-related genetic diseases (Kong et al., 2019). Among other readthrough molecules, a dipeptide-like hydrazide antibiotic negamycin, originally purified from Streptomyces purpeofuscus, appears more potent than aminoglycosides and less toxic, as do negamycin derivatives (Arakawa et al., 2003; Taguchi et al., 2014; Hamada et al., 2019) (Table 2).

For more than 10 years, various screening systems have been used to identify compounds more potent than aminoglycosides and ataluren (Fig. 3). The readthrough compounds (RTCs) RTC13, RTC14, RTC204, RTC219, GJ071, GJ072, NV2907, NV2909, NV2899 and NV2913 (Du et al., 2009, 2013; Tutone et al., 2020) (Table 2) have been identified and tested on different constructs and cell models of nonsense-mutation-related genetic diseases. In most cases, these molecules have shown a readthrough activity similar to that of ataluren or aminoglycosides such as gentamicin (G418) (Du et al., 2009; Tutone et al., 2020; GomezGrau et al., 2015). 
Among the compounds identified as promoting induced translational readthrough, some have remarkable characteristics. The anti-allergy and anti-asthma drug Amlexanox, for example, has shown the capacity to both inhibit NMD and activate readthrough of UGA, UAG, and UAA nonsense mutations (Atanasova et al., 2017; Banning, Schiff \& Tikkanen, 2017;

Gonzalez-Hilarion et al., 2012). The clinically approved molecule Escin has also been shown to exert this dual action (Mutyam et al., 2016). In theory, such molecules should be more effective than molecules that only activate readthrough, since inhibiting NMD leads to an increased amount of RNA substrates for readthrough (Linde et al., 2007; Gonzalez-Hilarion et al., 2012). It seems, however, that this is not an absolute rule, as some readthrough activators with no NMD-inhibiting action promote greater synthesis of full-length proteins than do dualaction molecules. For instance, the readthrough activators Lepista flaccida extract $\mathrm{H} 7$ and 2,6diaminopurine, which do not inhibit NMD, correct UGA and UAA (extract H7) or UGA only (2,6-diaminopurine) more effectively than dual-action G418 (Benhabiles et al., 2017; Trzaska et al., 2020; Correa-Cerro et al., 2005).

Clitocine is another molecule with a high readthrough-promoting capacity. However, this molecule, found in various mushroom species (including Leucopaxillus giganteus and Lepista flaccida) (Trzaska et al., 2020; Kubo et al., 1986; Wilde et al., 2007; Ren et al., 2008;

Benhabiles et al., 2017; Fortin et al., 2006) unfortunately shows high toxicity, which limits its potential therapeutic development (Fortin et al., 2006; Sun et al., 2012). The mode of action of clitocine has been studied. Interestingly, this molecule, whose structure resembles that of a nucleoside, is incorporated into RNA molecules during transcription, substituting for adenosines. Like adenosine, clitocine can preferentially pair with uracil, but it has been proposed that the translation termination factor eRF1 weakly recognizes stop codons containing clitocine, increasing the chance of near-cognate tRNA recruitment (Friesen et al., 2017). 
Cell culture conditions can also influence readthrough efficiency. In ribosome profiling experiments performed on the neural cell line PC12, oxygen and glucose deprivation were shown to inhibit programmed translational readthrough of 18 mRNAs with a UGA physiological stop codon followed by a cytosine: Fkbp1a, Hadhb, Hs1bp3, Klc1, LOC102554884, Mdh1, Mrto4, Nedd8, Nudcd2, Plat, Polr21, Ppp4c, Rfc2, Rnf111, Sec13, Slc7a1, Ssna1 and Thy1 (Andreev et al., 2015). Interestingly, this regulation occurs very

507 rapidly: less than 20 min after starting hypoxia and low glucose, programmed translational readthrough was strongly reduced. Although the mode of action is not clear, it could be related to the loss of protein hydroxylation at the decoding centre of the ribosome.

Other cell culture conditions that seem to potentiate PTC readthrough notably include serum starvation. In a medium containing $1 \%$ serum, the PTC-readthrough efficacy of aminoglycosides can increase two- to threefold without modifying the translation activity on the mRNA substrates, as demonstrated using a dual-reporter green fluorescent protein (GFP)blue fluorescent protein (BFP) construct (Wittenstein et al., 2019). How serum starvation potentiates the readthrough activity of aminoglycosides is not yet understood, but given the influence of serum on gene expression, it seems likely that specific gene products acting as cofactors are overexpressed or repressed.

\section{THERAPEUTIC INTEREST OF STOP CODON READTHROUGH}

Favouring stop codon readthrough to correct a nonsense mutation represents an attractive approach to the treatment of certain genetic diseases. About $11 \%$ of patients with a genetic disease carry a nonsense mutation responsible for its pathology (Mort et al., 2008). The use of readthrough molecules was first tested in patients with cystic fibrosis caused by a nonsense 
mutation in the CFTR gene. The aminoglycoside gentamicin was administered intravenously, at $2.5 \mathrm{mg} / \mathrm{kg}$ every $8 \mathrm{~h}$ for seven days, to five patients carrying nonsense mutations and five patients without nonsense mutation in CFTR (Clancy et al., 2001). The results showed a mild but encouraging rescue of CFTR expression and function. Another study on cystic fibrosis patients demonstrated that rescue of CFTR function depends strongly on the nonsense mutation: patients with the Y122X nonsense mutation seemed to respond better than patients carrying G542X, R1162X, or W1282X (Sermet-Gaudelus et al., 2007). Aminoglycosides (particularly gentamicin) have also been tested in patients with Duchenne muscular dystrophy (DMD) carrying a nonsense mutation in the DMD gene encoding dystrophin. Gentamicin has been tested in several studies with different protocols. In one study, four DMD patients with a nonsense mutation in the $D M D$ gene were treated daily for 14 days with gentamicin at 7.5 $\mathrm{mg} / \mathrm{kg}$ (Wagner et al., 2001). This study concluded that the administered gentamicin treatment was unable to promote the synthesis of full-length dystrophin protein. In another study, positive results were obtained by intravenous administration of $7.5 \mathrm{mg} / \mathrm{kg}$ gentamicin, once or twice a week for 6 months, to patients carrying a nonsense mutation in the $D M D$ gene, as compared to control patients carrying a frameshift mutation in the DMD gene (Malik et al., 2010). The treatment was well tolerated by patients, without any sign of toxicity. The level of dystrophin protein increased in gentamicin-treated patients carrying a nonsense mutation, indicating that readthrough of the nonsense mutation occurred. However, the physical strength of these patients was unaffected by the treatment, implying that dystrophin rescue was insufficient.

The non-aminoglycoside molecule ataluren has also been tested on cystic fibrosis and DMD patients carrying nonsense mutations. This molecule was well tolerated by patients. DMD patients received ataluren orally three times daily at 4-4-8 mg/kg, 10-10-20 mg/kg, or 20$20-40 \mathrm{mg} / \mathrm{kg}$ for 28 days. At the end of the study, dystrophin was detected in patients at the 
lowest and middle doses but not in patients at the highest dose (Namgoong \& Bertoni, 2016). After a 48-week exposure to ataluren or placebo, drug-treated patients showed no significant improvement in a 6-min walking-distance test as compared to the placebo group (Finkel et al., 2013; Bushby et al., 2014). For patients with cystic fibrosis caused by nonsense mutations, several phase II and III clinical trials have been completed. Physical improvement was observed in patients having received ataluren versus placebo, although this improvement remained modest (Kerem et al., 2008; Sermet-Gaudelus et al., 2010; Lee \& Dougherty, 2012). The results of the clinical trials performed with gentamicin or ataluren clearly demonstrate that it is possible to correct nonsense mutations by inducing PTC readthrough in patients. Although no cure for patients with nonsense-mutation-related genetic diseases is yet available, these encouraging results warrant both optimization of the tested protocols and a search for new therapeutic approaches.

\section{NEW DEVELOPMENTS AND THERAPEUTIC TARGETS}

As described below, aminoglycosides have high potential to correct nonsense mutations. Yet because of their oto- and nephrotoxicity, their clinical development has been limited (Hock \& Anderson, 1995; Mingeot-Leclercq \& Tulkens, 1999; Swan, 1997; Greenwood, 1959; Heck, Hinshaw \& Parsons, 1963; Matz, 1993; Wu et al., 2001). To address this issue, aminoglycoside derivatives have been synthesized and tested for the capacity to correct nonsense mutations while showing lower toxicity. Several molecules meeting these criteria appear to be good candidates for treating genetic diseases caused by nonsense mutations, their efficacy having been demonstrated on cell lines and in vivo mouse models (Goldmann et al., 2012; Nudelman et al., 2009, 2006; Shulman et al., 2014; Wang et al., 2012; Xue et al., 2014). One of these molecules, named ELX-02 (from Eloxx Pharmaceuticals), has already successfully passed clinical phase I (Leubitz et al., 2019), and clinical phase II is ongoing. 
ELX-02 is much less toxic than gentamicin or G418, and no nephrotoxicity has been detected. Its readthrough efficiency is similar to that of G418, making this molecule an excellent drug candidate (Brasell et al., 2019).

Regarding ataluren (from PTC Therapeutics), the quest to identify derivative molecules with higher efficacy has already begun. Molecules such as NV2445 and PTC414 seem to offer a slightly higher readthrough efficiency. Provided their toxicity is no higher than that of ataluren, they could represent optimized versions of this drug (Pibiri et al., 2018; Moosajee et al., 2016).

One of the biggest challenges is to identify low-toxicity molecules with a significantly higher readthrough efficiency than reference molecules such as G418. To identify readthrough molecules, many screening systems have been devised (Fig. 3). They are based on the use of either $(i)$ one cDNA encoding a fluorescent protein or enzyme, in which a stop codon has been introduced to interrupt the ORF and prevent synthesis of the functional protein (Fig. 3A) (Du et al., 2009; Manuvakhova et al., 2000; Welch et al., 2007; Burke \& Mogg, 1985; Sogaard, Jakobsen \& Justesen, 1999) or (ii) two cDNAs encoding fluorescent proteins or enzymes, separated by a stop codon (Fig. 3B) (Bidou et al., 2004; Xue et al., 2014; Cardno et al., 2009). In the latter case, the level of protein produced from the first cDNA is used to normalize measurements between samples, and the level of protein produced from the second ORF reflects the readthrough efficiency. The advantage of these constructs is that they are not spliced downstream of the premature termination codon, so that the corresponding mRNA is not subject to NMD (Lejeune \& Maquat, 2005). This makes it possible to identify molecules on the sole basis of their readthrough-promoting activity. However, with such constructs there is a risk of selecting molecules with low readthrough efficiency (and hence low therapeutic efficacy), as testing is done on mRNAs present in huge copy numbers. In addition, as the premRNAs of more than $90 \%$ of human genes are subject to splicing, the corresponding PTC- 
carrying mRNAs will be substrates for NMD, which will strongly reduce the copy number of substrates for readthrough. It is important to bear in mind that this is the prevailing situation in patient cells. To identify molecules capable of correcting nonsense mutations in these cells, screening systems should be designed with constructs subject to NMD. Such a screening system has been described: it consists of a cDNA encoding the firefly luciferase interrupted by an intron and an upstream PTC (Fig. 3C) (Benhabiles et al., 2017). It has been shown that the firefly luciferase pre-mRNA is spliced and the mRNA degraded by NMD. The luciferase activity measured in this screening system thus depends on the efficiency of readthrough occurring on the number of firefly luciferase mRNAs that have escaped NMD. This screening system has been used successfully to identify Lepista flaccida fungus extract $\mathrm{H} 7$ and 2,6diaminopurine as two highly potent correctors of nonsense mutations in human cells (Benhabiles et al., 2017; Trzaska et al., 2020).

Studies aiming to increase the effectiveness of readthrough compounds have identified some molecules that potentiate the readthrough activity of aminoglycosides (Table 3). Interestingly, these molecules do not promote readthrough by themselves. For example, the phthalimide derivative CDX5-1 increases about 180-fold the readthrough efficiency of G418 in both yeast and human cells (Baradaran-Heravi et al., 2016). More recently discovered potentiators of aminoglycosides include the antimalarial mefloquine (Ferguson et al., 2019) and 2aminothiazole-4-carboxamides (Rabea et al., 2019). How these molecules improve the readthrough efficiency of aminoglycosides is unclear, but by making it possible to administer lower doses of aminoglycosides, they should reduce aminoglycoside-linked toxic effects. As the use of screening systems to identify molecules with readthrough activity takes time and money, new targeted approaches are being or could be developed to promote efficient readthrough. One such approach is based on the mechanism of action of 2,6-diaminopurine, recently shown to promote readthrough of UGA premature stop codons by interfering with the 
function of filamentous temperature sensitive J1 (FTSJ1). This enzyme is a methyltransferase targeting position C34 of the tRNA carrying tryptophan and recognizing the UGG codon (Trzaska et al., 2020). Decreased C34 methylation allows this tRNA to recognize also the UGA stop codon (Trzaska et al., 2020). Hence, tRNA-modifying enzymes appear as interesting targets. This readthrough-activating strategy seems more effective than targeting the ribosome, but it remains to be validated through identification of new molecules targeting other tRNA-modification enzymes. Another potential target in the search for readthroughpromoting molecules is the ATP-binding domain 3/cytosolic thiouridylase subunit 1 (ATPBD3/CTU1) protein. This tRNA-modifying enzyme notably acts at the anticodon loop of near-cognate tRNAs, enabling them to recognize a UAG or UAA stop codon (Blanchet $e t$ al., 2018).

Pseudouridylation is another post-transcriptional modification occurring on RNA molecules that might be used to activate stop codon readthrough. Interestingly, pseudouridylation converts a uridine to a pseudouridine, which can pair with all four conventional bases (Kierzek et al., 2014). Protocols have been designed to induce site-directed pseudouridylation at the uridine constituting the first base of all three stop codons (Wu, Huang \& Yu, 2015). The idea is that the presence of a pseudouridine at this position will stabilize near-cognate tRNAs and increase basal readthrough of this stop codon.

A final approach worth mentioning is direct modification of tRNA anticodon sequences, enabling them to pair with stop codons. Such tRNAs, called suppressor tRNAs, have been investigated as potential therapeutics for almost 40 years (Temple et al., 1982), and research is still ongoing. Very recently, investigators have described a high-throughput cloning system for identifying tRNAs that suppress nonsense mutations with high efficiency (Lueck et al., 2019). Interestingly, a comparative study of suppressor tRNAs and readthrough molecules such as gentamicin and G418 demonstrated a superior nonsense-mutation-correcting 
efficiency of the tested tRNAs. A legitimate question is whether such molecules affect translation termination at physiological stop codons. Lueck et al. (2019), using ribosome profiling, showed that suppressor tRNAs do read through physiological stop codons in rare cases, but that this readthrough is much less efficient than PTC readthrough. A limitation of this very promising approach remains delivery of the suppressor tRNA to the cells of patients liable to benefit from correction of a nonsense mutation responsible for a genetic disease.

\section{CONCLUSIONS}

(1) Stop codon readthrough is a natural process resulting in continuation of translation beyond the first stop codon encountered in phase with the translation initiation codon. The mechanism determining whether the translation machinery recruits a tRNA to promote translational readthrough, or the translation termination complex to the stop codon remains poorly understood.

(2) Several types of stop codon readthrough can be identified. Non-programmed translational readthrough or basal stop codon readthrough arises as a translational error without any cis and/or trans facilitator elements and at a very low rate. Programmed translational readthrough involves cis and/or trans activator elements, and often reaches more than $20 \%$ efficiency. The cis and trans elements described herein constitute first steps in understanding of the molecular mechanisms involved. Induced translational readthrough involves small molecules that increase the recruitment of near-cognate tRNAs when the ribosome pauses at a stop codon. (3) Several regulator elements have been reported to modulate stop codon readthrough. The nucleotide sequence in the vicinity of the stop codon has been reported strongly to influence the stop codon readthrough rate. RNAs, proteins and small molecules also play a role in stop codon readthrough efficacy. Given the therapeutic potential of activators of PTC-readthrough, regulator elements responsible for high efficiency of readthrough deserve in-depth study. It is 
essential to fill the gaps in our knowledge of the molecular events leading to stop codon readthrough and its regulation. This should be accomplished by studying the molecular mechanism of stop codon recognition and the mode of action of readthrough molecules. (4) None of the therapeutic approaches under development to correct nonsense mutations responsible for genetic diseases has yet come to fruition. However, the diversity of strategies explored makes the field of nonsense mutation correction highly dynamic. Step by step, personalized therapeutic strategies based on stop codon readthrough are taking form. They should, in the near future, yield treatments for genetic diseases caused by nonsense mutations.

\section{ACKNOWLEDGMENTS}

M.P. is supported by a grant from la Région Hauts-de-France and l'Université de Lille. F.L. is an Inserm researcher supported by funding from Vaincre la mucoviscidose, La Ligue Contre le Cancer and the GIP Cancéropôle Nord Ouest.

\section{REFERENCES}

Agris, P. F., Narendran, A., SARAchan, K., Vare, V. Y. P. \& ERUySAL, E. (2017). The importance of being modified: The role of rna modifications in translational fidelity. Enzymes 41, 1-50.

alarcon, C. R., Goodarzi, H., Lee, H., LiU, X., Tavazole, S. \& Tavazole, S. F. (2015). Hnrnpa2b1 is a mediator of $\mathrm{m}$ (6)a-dependent nuclear rna processing events. Cell 162(6), 1299-1308.

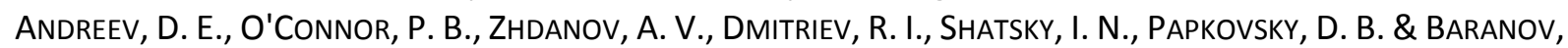
P. V. (2015). Oxygen and glucose deprivation induces widespread alterations in mrna translation within 20 minutes. Genome Biology 16, 90.

arakawa, M., Shiozuka, M., NakaYama, Y., Hara, T., Hamada, M., Kondo, S., IKEDA, D., Takahashi, Y., SaWA, R., Nonomura, Y., SHeYkHoleslami, K., Kondo, K., Kaga, K., KitamuRa, T., SuzUki-MiYagoe, $\mathrm{Y}$. , et al. (2003). Negamycin restores dystrophin expression in skeletal and cardiac muscles of mdx mice. The Journal of Biochemistry 134(5), 751-758.

atanasova, V. S., Jiang, Q., Prisco, M., Gruber, C., Pinon Hofbauer, J., Chen, M., Has, C., BrucknerTuderman, L., McGrath, J. A., UitTo, J. \& SoUth, A. P. (2017). Amlexanox enhances premature termination codon read-through in col7a1 and expression of full length type vii collagen: Potential therapy for recessive dystrophic epidermolysis bullosa. Journal of Investigative Dermatology 137(9), 1842-1849.

BANNING, A., SCHIFF, M. \& TIKKANEN, R. (2017). Amlexanox provides a potential therapy for nonsense mutations in the lysosomal storage disorder aspartylglucosaminuria. Biochimica et Biophysica Acta 1864(3), 668-675.

Baradaran-Heravi, A., Balgi, A. D., Zimmerman, C., Chol, K., Shidmoossavee, F. S., Tan, J. S., Bergeaud, C., Krause, A., Flibotte, S., Shimizu, Y., Anderson, H. J., Mouly, V., Jan, E., Pfeifer, T., Jaquith, J. B., 
et al. (2016). Novel small molecules potentiate premature termination codon readthrough by aminoglycosides. Nucleic Acids Research 44(14), 6583-6598.

Bednarova, A., hanna, M., Durham, I., VanCleave, T., England, A., Chaudhuri, A. \& Krishnan, N. (2017). Lost in translation: Defects in transfer rna modifications and neurological disorders. Frontiers in Molecular Neuroscience 10, 135.

BEIER, H. \& GRIMM, M. (2001). Misreading of termination codons in eukaryotes by natural nonsense suppressor trnas. Nucleic Acids Research 29(23), 4767-4782.

Beissel, C., NeumanN, B., UhSe, S., Hampe, I., KARKI, P. \& KRebBer, H. (2019). Translation termination depends on the sequential ribosomal entry of erf1 and erf3. Nucleic Acids Research 47(9), 4798-4813.

Benhabiles, H., Gonzalez-Hilarion, S., Amand, S., Bailly, C., Prevotat, A., Reix, P., Hubert, D., Adriaenssens, E., Rebuffat, S., Tulasne, D. \& Lejeune, F. (2017). Optimized approach for the identification of highly efficient correctors of nonsense mutations in human diseases. PLOS One 12(11), e0187930.

Beriault, V., Clement, J. F., levesque, K., Lebel, C., Yong, X., Chabot, B., Cohen, E. A., Cochrane, A. W., RIGBY, W. F. \& MOULAND, A. J. (2004). A late role for the association of hnrnp a2 with the hiv-1 hnrnp a2 response elements in genomic rna, gag, and vpr localization. The Journal of Biological Chemistry 279(42), 44141-44153.

Beznoskova, P., WAgner, S., JANSEN, M. E., VON DER HAAR, T. \& VAlASEK, L. S. (2015). Translation initiation factor eif3 promotes programmed stop codon readthrough. Nucleic Acids Research 43(10), 5099-5111.

Bezzerri, V., ApI, M., Allegri, M., Fabrizzi, B., Corey, S. J. \& Cipolli, M. (2020). Nonsense suppression therapy: New hypothesis for the treatment of inherited bone marrow failure syndromes. International Journal of Molecular Sciences 21(13), 10.3390/ijms21134672

Bidou, L., hatin, I., Perez, N., Allamand, V., Panthier, J. J. \& Rousset, J. P. (2004). Premature stop codons involved in muscular dystrophies show a broad spectrum of readthrough efficiencies in response to gentamicin treatment. Gene Therapy 11(7), 619-627.

Blanchet, S., Cornu, D., hatin, I., Grosjean, H., Bertin, P. \& NAMY, O. (2018). Deciphering the reading of the genetic code by near-cognate trna. Proceedings of the National Academy of Sciences of the United States of America 115(12), 3018-3023.

BonettI, B., Fu, L., Moon, J. \& BedWelL, D. M. (1995). The efficiency of translation termination is determined by a synergistic interplay between upstream and downstream sequences in saccharomyces cerevisiae. Journal of Molecular Biology 251(3), 334-345.

Brasell, E. J., Chu, L. L., Akpa, M. M., Eshkar-Oren, I., Alroy, I., Corsini, R., GilfiX, B. M., Yamanaka, Y., Huertas, P. \& GoOdYER, P. (2019). The novel aminoglycoside, elx-02, permits ctnsw $138 x$ translational read-through and restores lysosomal cystine efflux in cystinosis. PLoS One 14(12), e0223954.

Brown, A., Shao, S., Murray, J., Hegde, R. S. \& Ramakrishnan, V. (2015). Structural basis for stop codon recognition in eukaryotes. Nature 524(7566), 493-496.

Brown, C. M., Stockwell, P. A., Trotman, C. N. \& TATE, W. P. (1990). Sequence analysis suggests that tetra-nucleotides signal the termination of protein synthesis in eukaryotes. Nucleic Acids Research 18(21), 6339-6345.

BURKE, J. F. \& MOGG, A. E. (1985). Suppression of a nonsense mutation in mammalian cells in vivo by the aminoglycoside antibiotics g-418 and paromomycin. Nucleic Acids Res 13(17), 6265-6272.

Bushby, K., Finkel, R., Wong, B., Barohn, R., Campbell, C., Comi, G. P., Connolly, A. M., Day, J. W., Flanigan, K. M., Goemans, N., Jones, K. J., Mercuri, E., Quinlivan, R., Renfroe, J. B., Russman, B., et al. (2014). Ataluren treatment of patients with nonsense mutation dystrophinopathy. Muscle Nerve 50(4), 477-487.

Cardno, T. S., Poole, E. S., Mathew, S. F., Graves, R. \& TAte, W. P. (2009). A homogeneous cell-based bicistronic fluorescence assay for high-throughput identification of drugs that perturb viral gene recoding and read-through of nonsense stop codons. RNA 15(8), 1614-1621. 
Carter, A. P., Clemons, W. M., Brodersen, D. E., Morgan-Warren, R. J., Wimberly, B. T. \& Ramakrishnan, V. (2000). Functional insights from the structure of the 30 s ribosomal subunit and its interactions with antibiotics. Nature 407(6802), 340-348.

CASSAN, M. \& ROUSSET, J. P. (2001). Uag readthrough in mammalian cells: Effect of upstream and downstream stop codon contexts reveal different signals. BMC Molecular Biology 2, 3.

Chittum, H. S., Lane, W. S., Carlson, B. A., Roller, P. P., lung, F. D., Lee, B. J. \& Hatfield, D. L. (1998). Rabbit beta-globin is extended beyond its uga stop codon by multiple suppressions and translational reading gaps. Biochemistry 37(31), 10866-10870.

Clancy, J. P., Bebok, Z., Ruiz, F., King, C., Jones, J., Walker, L., Greer, H., Hong, J., Wing, L., Macaluso, M., LYRENE, R., SORSCHER, E. J. \& BedWELL, D. M. (2001). Evidence that systemic gentamicin suppresses premature stop mutations in patients with cystic fibrosis. American Journal of Respiratory and Critical Care Medicine 163(7), 1683-1692.

Correa-Cerro, L. S., Wassif, C. A., Waye, J. S., Krakowiak, P. A., Cozma, D., Dobson, N. R., LeVin, S. W., Anadiotis, G., Steiner, R. D., Krajewska-Walasek, M., Nowaczyk, M. J. \& Porter, F. D. (2005). Dhcr7 nonsense mutations and characterisation of mrna nonsense mediated decay in smithlemli-opitz syndrome. Journal of Medical Genetics 42(4), 350-357.

CRICK, F. H. (1966). Codon--anticodon pairing: The wobble hypothesis. Journal of Molecular Biology 19(2), 548-555.

Cutting, G. R., Kasch, L. M., Rosenstein, B. J., TSUI, L. C., Kazazian, H. H., JR. \& Antonarakis, S. E. (1990). Two patients with cystic fibrosis, nonsense mutations in each cystic fibrosis gene, and mild pulmonary disease. New England Journal of Medicine 323(24), 1685-1689.

DABROWSKI, M., BUKOWY-BIERYLLO, Z. \& ZiETKIEWICZ, E. (2018). Advances in therapeutic use of a drugstimulated translational readthrough of premature termination codons. Mol Med 24(1), 25.

DeVER, T. E., KINZY, T. G. \& PAVITT, G. D. (2016). Mechanism and regulation of protein synthesis in saccharomyces cerevisiae. Genetics 203(1), 65-107.

Du, L., Damoiseaux, R., Nahas, S., GaO, K., Hu, H., Pollard, J. M., Goldstine, J., Jung, M. E., Henning, S. M., BERTONI, C. \& GATTI, R. A. (2009). Nonaminoglycoside compounds induce readthrough of nonsense mutations. Journal of Experimental Medicine 206(10), 2285-2297.

Du, L., Jung, M. E., Damoiseaux, R., Completo, G., Fike, F., Ku, J. M., Nahas, S., Piao, C., Hu, H. \& GatTi, R. A. (2013). A new series of small molecular weight compounds induce read through of all three types of nonsense mutations in the atm gene. Molecular Therapy 21(9), 1653-1660.

Duechler, M., LeszCzynskA, G., SochackA, E. \& NAWrot, B. (2016). Nucleoside modifications in the regulation of gene expression: Focus on trna. Cellular and Molecular Life Sciences 73(16), 3075-3095.

DunN, J. G., Foo, C. K., Belletier, N. G., Gavis, E. R. \& Weissman, J. S. (2013). Ribosome profiling reveals pervasive and regulated stop codon readthrough in drosophila melanogaster. Elife 2, e01179.

Eswarappa, S. M., Potdar, A. A., Koch, W. J., Fan, Y., VAsu, K., Lindner, D., Willard, B., Graham, L. M., DiCorleto, P. E. \& FoX, P. L. (2014). Programmed translational readthrough generates antiangiogenic vegf-ax. Cell 157(7), 1605-1618.

Fearon, K., McClendon, V., Bonetti, B. \& Bedwell, D. M. (1994). Premature translation termination mutations are efficiently suppressed in a highly conserved region of yeast ste6p, a member of the atp-binding cassette (abc) transporter family. Journal of Biological Chemistry 269(27), 17802-17808.

Feng, Y. X., Copeland, T. D., Oroszlan, S., ReIn, A. \& LeVIN, J. G. (1990). Identification of amino acids inserted during suppression of uaa and uga termination codons at the gag-pol junction of moloney murine leukemia virus. Proceedings of the National Academy of Sciences of the United States of America 87(22), 8860-8863.

Ferguson, M. W., Gerak, C. A. N., Chow, C. C. T., Rastelli, E. J., Elmore, K. E., Stahl, F., HosseiniFarahabadi, S., Baradaran-Heravi, A., Coltart, D. M. \& Roberge, M. (2019). The antimalarial drug mefloquine enhances tp53 premature termination codon readthrough by aminoglycoside g418. PLoS One 14(5), e0216423. 
Finkel, R. S., Flanigan, K. M., Wong, B., Bonnemann, C., Sampson, J., SWeeney, H. L., Reha, A., Northcutt, V. J., Elfring, G., BARTh, J. \& Peltz, S. W. (2013). Phase 2a study of ataluren-mediated dystrophin production in patients with nonsense mutation duchenne muscular dystrophy. PLoS One 8(12), e81302.

FirTh, A. E., Wills, N. M., GeStelAnd, R. F. \& AtKInS, J. F. (2011). Stimulation of stop codon readthrough: Frequent presence of an extended 3' rna structural element. Nucleic Acids Research 39(15), 6679-6691.

Floquet, C., Hatin, I., Rousset, J. P. \& Bidou, L. (2012). Statistical analysis of readthrough levels for nonsense mutations in mammalian cells reveals a major determinant of response to gentamicin. PLoS Genetics 8(3), e1002608.

Fortin, H., TOMASI, S., Delcros, J. G., BANSARD, J. Y. \& Boustie, J. (2006). In vivo antitumor activity of clitocine, an exocyclic amino nucleoside isolated from lepista inversa. ChemMedChem 1(2), 189-196.

FreitAG, J., ASt, J. \& Bolker, M. (2012). Cryptic peroxisomal targeting via alternative splicing and stop codon read-through in fungi. Nature 485(7399), 522-525.

Friesen, W. J., Trotta, C. R., Tomizawa, Y., Zhuo, J., Johnson, B., Sierra, J., Roy, B., Weetall, M., Hedrick, J., Sheedy, J., TAKASUgI, J., MoON, Y. C., BABU, S., BAIAZITOV, R., LeSZYK, J. D., et al. (2017). The nucleoside analog clitocine is a potent and efficacious readthrough agent. $R N A$ 23(4), 567577.

GELLER, A. I. \& RICH, A. (1980). A uga termination suppression trnatrp active in rabbit reticulocytes. Nature 283(5742), 41-46.

Goldmann, T., Overlack, N., Moller, F., Belakhov, V., van Wyk, M., BaAsov, T., Wolfrum, U. \& NagelWolfRUM, K. (2012). A comparative evaluation of nb30, nb54 and ptc124 in translational read-through efficacy for treatment of an ush1c nonsense mutation. EMBO Molecular Medicine 4(11), 1186-1199.

Gomez-Grau, M., Garrido, E., Cozar, M., Rodriguez-Sureda, V., Dominguez, C., Arenas, C., Gatti, R. A., Cormand, B., Grinberg, D. \& VilageliU, L. (2015). Evaluation of aminoglycoside and nonaminoglycoside compounds for stop-codon readthrough therapy in four lysosomal storage diseases. PLoS One 10(8), e0135873.

Gonzalez-Hilarion, S., Beghyn, T., Jia, J., Debreuck, N., Berte, G., Mamchaoui, K., Mouly, V., Gruenert, D. C., DEPREZ, B. \& LEJEUNE, F. (2012). Rescue of nonsense mutations by amlexanox in human cells. Orphanet Journal of Rare Diseases 7, 58.

GREENWOOD, G. J. (1959). Neomycin ototoxicity; report of a case. AMA Arch Otolaryngol 69(4), 390397.

GrosjeAN, H. \& Westhof, E. (2016). An integrated, structure- and energy-based view of the genetic code. Nucleic Acids Research 44(17), 8020-8040.

Gross, T., Siepmann, A., Sturm, D., Windgassen, M., Scarcelli, J. J., Seedorf, M., Cole, C. N. \& Krebber, H. (2007). The dead-box rna helicase dbp5 functions in translation termination. Science 315(5812), 646-649.

GUPTA, P. \& LI, Y. R. (2018). Upf proteins: Highly conserved factors involved in nonsense mrna mediated decay. Molecular Biology Reports 45(1), 39-55.

haAs, M., Vlcek, V., Balabanov, P., Salmonson, T., Bakchine, S., Markey, G., Weise, M., Schlosser-Weber, G., Brohmann, H., Yerro, C. P., Mendizabal, M. R., Stoyanova-Beninska, V. \& Hillege, H. L. (2015). European medicines agency review of ataluren for the treatment of ambulant patients aged 5 years and older with duchenne muscular dystrophy resulting from a nonsense mutation in the dystrophin gene. Neuromuscular Disorders 25(1), 5-13.

Hagervall, T. G., ERICSON, J. U., EsberG, K. B., LI, J. N. \& BJORK, G. R. (1990). Role of trna modification in translational fidelity. Biochimica et Biophysica Acta 1050(1-3), 263-266.

hamada, K., Omura, N., Taguchi, A., Baradaran-Heravi, A., Kotake, M., Aral, M., Takayama, K., Taniguchi, A., ROBERGE, M. \& HAYASHI, Y. (2019). New negamycin-based potent readthrough derivative effective against tga-type nonsense mutations. ACS Medicinal Chemistry Letters 10(10), 1450-1456. 
HARGER, J. W. \& DINMAN, J. D. (2004). Evidence against a direct role for the upf proteins in frameshifting or nonsense codon readthrough. RNA 10(11), 1721-1729.

HARReLl, L., MelCheR, U. \& ATKINS, J. F. (2002). Predominance of six different hexanucleotide recoding signals 3' of read-through stop codons. Nucleic Acids Research 30(9), 2011-2017.

HE, F. \& JACOBSON, A. (2015). Nonsense-mediated mrna decay: Degradation of defective transcripts is only part of the story. Annual Review of Genetics 49, 339-366.

HeCK, W. E., HinshaW, H. C. \& PARSONS, H. G. (1963). Auditory ototoxicity in tuberculosis patients treatedwith a report of the incidence of hearing loss in a series of 1,150 cases. JAMA 186, 1820.

HOCK, R. \& ANDERSON, R. J. (1995). Prevention of drug-induced nephrotoxicity in the intensive care unit. Journal of Critical Care 10(1), 33-43.

Houck-Loomis, B., Durney, M. A., Salguero, C., Shankar, N., Nagle, J. M., Goff, S. P. \& D'Souza, V. M. (2011). An equilibrium-dependent retroviral mrna switch regulates translational recoding. Nature 480(7378), 561-564.

Howard, M. T., ShiRTs, B. H., Petros, L. M., Flanigan, K. M., Gesteland, R. F. \& Atkins, J. F. (2000). Sequence specificity of aminoglycoside-induced stop condon readthrough: Potential implications for treatment of duchenne muscular dystrophy. Annals of Neurology 48(2), 164169.

IVAnov, P. V., Gehring, N. H., KUnZ, J. B., Hentze, M. W. \& KUloziK, A. E. (2008). Interactions between upf1, erfs, pabp and the exon junction complex suggest an integrated model for mammalian nmd pathways. EMBO Journal 27(5), 736-747.

JiA, J., Werkmeister, E., Gonzalez-Hilarion, S., LeRoy, C., GRUenert, D. C., LAFOnT, F., TUlasne, D. \& Lejeune, F. (2017). Premature termination codon readthrough in human cells occurs in novel cytoplasmic foci and requires upf proteins. Journal of Cell Science 130(18), 3009-3022.

Jungreis, I., Chan, C. S., Waterhouse, R. M., Fields, G., Lin, M. F. \& Kellis, M. (2016). Evolutionary dynamics of abundant stop codon readthrough. Molecular Biology and Evolution 33(12), 3108-3132.

KAPUR, M., Monaghan, C. E. \& ACKeRMAN, S. L. (2017). Regulation of mrna translation in neurons-a matter of life and death. Neuron 96(3), 616-637.

KeEling, K. M., SALAS-MARCo, J., OSHeRovich, L. Z. \& BedWell, D. M. (2006). Tpa1p is part of an mrnp complex that influences translation termination, mrna deadenylation, and mrna turnover in saccharomyces cerevisiae. Molecular and Cellular Biology 26(14), 5237-5248.

Kerem, B. S., Zielenski, J., MARKIEWICZ, D., Bozon, D., GaZit, E., YAhAV, J., KenNedy, D., RIORdAN, J. R., ColLINS, F. S., ROMMENS, J. M. \& TSUI, L.C. (1990). Identification of mutations in regions corresponding to the two putative nucleotide (atp)-binding folds of the cystic fibrosis gene. Proceedings of the National Academy of Sciences of the United States of America 87(21), 8447-8451.

Kerem, E., Hirawat, S., Armoni, S., Yaakov, Y., Shoseyov, D., Cohen, M., Nissim-Rafinia, M., Blau, H., Rivin, J., AVIRAm, M., Elfring, G. L., NorthCutt, V. J., Miller, L. L., Kerem, B. \& WilsChanski, M. (2008). Effectiveness of ptc124 treatment of cystic fibrosis caused by nonsense mutations: $A$ prospective phase ii trial. The Lancet 372(9640), 719-727.

Kerem, E., Konstan, M. W., De Boeck, K., Accurso, F. J., Sermet-Gaudelus, I., Wilschanski, M., Elborn, J. S., Melotti, P., Bronsveld, I., Fajac, I., Malfroot, A., Rosenbluth, D. B., Walker, P. A., McColley, S. A., KNOOP, C., et al. (2014). Ataluren for the treatment of nonsense-mutation cystic fibrosis: A randomised, double-blind, placebo-controlled phase 3 trial. The Lancet Respiratory Medicine 2(7), 539-547.

Kierzek, E., Malgowska, M., Lisowiec, J., Turner, D. H., Gdaniec, Z. \& Kierzek, R. (2014). The contribution of pseudouridine to stabilities and structure of rnas. Nucleic Acids Research 42(5), 3492-3501.

KLePPE, A. S. \& BORNBERG-BAUER, E. (2018). Robustness by intrinsically disordered c-termini and translational readthrough. Nucleic Acids Research 46(19), 10184-10194. 
Kong, R., LaSkin, O. L., KaushiK, D., JiN, F., MA, J., McIntosh, J., SOuZA, M. \& Almstead, N. (2019). Ataluren pharmacokinetics in healthy japanese and caucasian subjects. Clinical Pharmacology in Drug Development 8(2), 172-178.

KUBO, I., KIM, M., WOOD, W. F. \& NAOKI, H. (1986). Clitocine, a new insecticidal nucleoside from the mushroom clitocybe inversa. Tetrahedron Letters 27, 4277-4280.

KUROSAKI, T. \& MAQUAT, L. E. (2016). Nonsense-mediated mrna decay in humans at a glance. Journal of Cell Science 129(3), 461-467.

KUZMIAK, H. A. \& MAQUAT, L. E. (2006). Applying nonsense-mediated mrna decay research to the clinic: Progress and challenges. Trends in Molecular Medicine 12(7), 306-316.

LABUNSKYy, V. M., HATFIELD, D. L. \& GLADYSHEV, V. N. (2014). Selenoproteins: Molecular pathways and physiological roles. Physiological Reviews 94(3), 739-777.

LEE, H. L. \& Dougherty, J. P. (2012). Pharmaceutical therapies to recode nonsense mutations in inherited diseases. Pharmacology \& Therapeutics 136(2), 227-266.

LEJEUNE, F. (2017). Nonsense-mediated mrna decay at the crossroads of many cellular pathways. $B M B$ Reports 50, 175-185.

LEJEUne, F. \& MAQUAT, L. E. (2005). Mechanistic links between nonsense-mediated mrna decay and pre-mrna splicing in mammalian cells. Current Opinion in Cell Biology 17(3), 309-315.

Leubitz, A., Frydman-Marom, A., Sharpe, N., van Duzer, J., Campbell, K. C. M. \& Vanhoutte, F. (2019). Safety, tolerability, and pharmacokinetics of single ascending doses of elx-02, a potential treatment for genetic disorders caused by nonsense mutations, in healthy volunteers. Clinical Pharmacology in Drug Development 8(8), 984-994.

Levesque, K., halvorsen, M., Abrahamyan, L., Chatel-Chaix, L., Poupon, V., Gordon, H., DesGroseillers, L., GATIGNOL, A. \& MOULAND, A. J. (2006). Trafficking of hiv-1 rna is mediated by heterogeneous nuclear ribonucleoprotein a2 expression and impacts on viral assembly. Traffic 7(9), 11771193.

LI, Y., WANG, X., LI, C., HU, S., YU, J. \& SONG, S. (2014). Transcriptome-wide n(6)-methyladenosine profiling of rice callus and leaf reveals the presence of tissue-specific competitors involved in selective mrna modification. RNA Biology 11(9), 1180-1188.

lin, M. F., Carlson, J. W., Crosby, M. A., Matthews, B. B., Yu, C., Park, S., Wan, K. H., Schroeder, A. J., Gramates, L. S., St Pierre, S. E., Roark, M., Wiley, K. L., JR., Kulathinal, R. J., Zhang, P., Myrick, K. V., et al. (2007). Revisiting the protein-coding gene catalog of drosophila melanogaster using 12 fly genomes. Genome Research 17(12), 1823-1836.

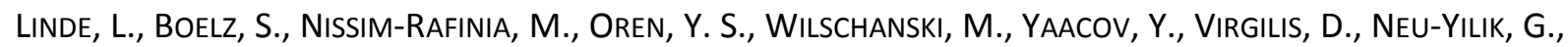
KULOZIK, A. E., KEREM, E. \& KEREM, B. (2007). Nonsense-mediated mrna decay affects nonsense transcript levels and governs response of cystic fibrosis patients to gentamicin. Journal of Clinical Investigation 117(3), 683-692.

loenarz, C., Sekirnik, R., Thalhammer, A., Ge, W., Spivakovsky, E., Mackeen, M. M., McDonough, M. A., CoCKMAN, M. E., Kessler, B. M., RATCliffe, P. J., Wolf, A. \& SChOFIELD, C. J. (2014). Hydroxylation of the eukaryotic ribosomal decoding center affects translational accuracy. Proceedings of the National Academy of Sciences of the United States of America 111(11), 4019-4024.

Loughran, G., Chou, M. Y., IVAnov, I. P., Jungreis, I., Kellis, M., Kiran, A. M., Baranov, P. V. \& Atkins, J. F. (2014). Evidence of efficient stop codon readthrough in four mammalian genes. Nucleic Acids Research 42(14), 8928-8938.

Loughran, G., Jungreis, I., Tzani, I., Power, M., Dmitriev, R. I., IVanov, I. P., Kellis, M. \& AtKins, J. F. (2018). Stop codon readthrough generates a c-terminally extended variant of the human vitamin d receptor with reduced calcitriol response. The Journal of Biological Chemistry 293(12), 4434-4444.

lueck, J. D., Yoon, J. S., Perales-Puchalt, A., Mackey, A. L., Infield, D. T., Behlke, M. A., Pope, M. R., Weiner, D. B., SKACH, W. R., McCray, P. B., JR. \& AHERN, C. A. (2019). Engineered transfer rnas for suppression of premature termination codons. Nature Communications 10(1), 822.

Malik, V., Rodino-Klapac, L. R., ViOllet, L., WAll, C., King, W., Al-DAHHAK, R., LeWIS, S., SHILliNG, C. J., Kota, J., Serrano-Munuera, C., hayes, J., Mahan, J. D., Campbell, K. J., BanWell, B., Dasouki, M., 
et al. (2010). Gentamicin-induced readthrough of stop codons in duchenne muscular dystrophy. Annals of Neurology 67(6), 771-780.

ManuvakHova, M., Keeling, K. \& BedWelL, D. M. (2000). Aminoglycoside antibiotics mediate contextdependent suppression of termination codons in a mammalian translation system. RNA 6(7), 1044-1055.

Martorell, L., Cortina, V., Parra, R., Barquinero, J. \& Vidal, F. (2020). Variable readthrough responsiveness of nonsense mutations in hemophilia a. Haematologica 105(2), 508-518.

MATZ, G. J. (1993). Aminoglycoside cochlear ototoxicity. Otolaryngologic Clinics of North America 26(5), 705-712.

McCaughan, K. K., Brown, C. M., Dalphin, M. E., BerRy, M. J. \& TATE, W. P. (1995). Translational termination efficiency in mammals is influenced by the base following the stop codon. Proceedings of the National Academy of Sciences of the United States of America 92(12), 5431-5435.

MERRICK, W. C. (1992). Mechanism and regulation of eukaryotic protein synthesis. Microbiological Reviews 56(2), 291-315.

Meyer, K. D., Saletore, Y., Zumbo, P., Elemento, O., Mason, C. E. \& Jaffrey, S. R. (2012). Comprehensive analysis of mrna methylation reveals enrichment in $3^{\prime}$ utrs and near stop codons. Cell 149(7), 1635-1646.

Mikhailova, T., Shuvalova, E., Ivanov, A., Susorov, D., Shuvalov, A., Kolosov, P. M. \& Alkalaeva, E. (2017). Rna helicase ddx19 stabilizes ribosomal elongation and termination complexes. Nucleic Acids Research 45(3), 1307-1318.

Mingeot-LeCleRCQ, M. P. \& TUlKens, P. M. (1999). Aminoglycosides: Nephrotoxicity. Antimicrobial Agents and Chemotherapy 43(5), 1003-1012.

Moosajee, M., Tracey-White, D., Smart, M., Weetall, M., Torriano, S., Kalatzis, V., Da Cruz, L., Coffey, P., WEBSTER, A. R. \& WELCH, E. (2016). Functional rescue of rep1 following treatment with ptc124 and novel derivative ptc-414 in human choroideremia fibroblasts and the nonsensemediated zebrafish model. Human Molecular Genetics 25(16), 3416-3431.

MoRAIS, P., ADACHI, H. \& YU, Y. T. (2020). Suppression of nonsense mutations by new emerging technologies. International Journal of Molecular Sciences 21(12, 4394).

MORI, N., FUnATSU, Y., HIRUTA, K. \& GOTO, S. (1985). Analysis of translational fidelity of ribosomes with protamine messenger rna as a template. Biochemistry 24(5), 1231-1239.

Mort, M., IVANov, D., CoOper, D. N. \& Chuzhanova, N. A. (2008). A meta-analysis of nonsense mutations causing human genetic disease. Human Mutation 29(8), 1037-1047.

Muramatsu, T., HeCKMANN, K., KITANAKA, C. \& KUCHINO, Y. (2001). Molecular mechanism of stop codon recognition by erf1: A wobble hypothesis for peptide anticodons. FEBS Lett 488(3), 105-109.

Mutyam, V., Du, M., XUE, X., Keeling, K. M., White, E. L., BostWick, J. R., RASMUSSEN, L., LIU, B., MAZUR, M., Hong, J. S., FAlK LibBY, E., LIANG, F., SHANG, H., MeNSE, M., SUto, M. J., et al. (2016). Discovery of clinically approved agents that promote suppression of cystic fibrosis transmembrane conductance regulator nonsense mutations. American Journal of Respiratory and Critical Care Medicine 194(9), 1092-1103.

NAMgoong, J. H. \& BertonI, C. (2016). Clinical potential of ataluren in the treatment of duchenne muscular dystrophy. Degenerative Neurological and Neuromuscular Disease 13(6), 37-48.

NAMY, O., HATIN, I. \& ROUSSET, J. P. (2001). Impact of the six nucleotides downstream of the stop codon on translation termination. EMBO reports 2(9), 787-793.

Neu-Yilik, G., Raimondeau, E., Eliseev, B., Yeramala, L., Amthor, B., Deniaud, A., Huard, K., Kerschgens, K., HeNtZE, M. W., SCHAfFitzel, C. \& KULOZIK, A. E. (2017). Dual function of upf3b in early and late translation termination. EMBO Journal 36(20), 2968-2986.

Nudelman, I., Rebibo-Sabbah, A., Cherniavsky, M., Belakhov, V., HainRichson, M., Chen, F., SChacht, J., PILCH, D. S., BEN-YOSEF, T. \& BAASOV, T. (2009). Development of novel aminoglycoside (nb54) with reduced toxicity and enhanced suppression of disease-causing premature stop mutations. Journal of Medicinal Chemistry 52(9), 2836-2845. 
Nudelman, I., Rebibo-Sabbah, A., Shallom-Shezifi, D., HainRichson, M., Stahl, I., Ben-Yosef, T. \& BaAsov, T. (2006). Redesign of aminoglycosides for treatment of human genetic diseases caused by premature stop mutations. Bioorganic \& Medicinal Chemistry Letters 16(24), 6310-6315.

Ogle, J. M., CaRTeR, A. P. \& RAMAKRISHnAN, V. (2003). Insights into the decoding mechanism from recent ribosome structures. Trends in Biochemical Sciences 28(5), 259-266.

PHILLIPS-JONES, M. K., WATSON, F. J. \& MARTIN, R. (1993). The 3' codon context effect on uag suppressor trna is different in escherichia coli and human cells. Journal of Molecular Biology 233(1), 1-6.

PibiRI, I., LentinI, L., Melfi, R., Tutone, M., Baldassano, S., Ricco Galluzzo, P., Di Leonardo, A. \& Pace, A. (2018). Rescuing the cftr protein function: Introducing 1,3,4-oxadiazoles as translational readthrough inducing drugs. European Journal of Medicinal Chemistry 159, 126-142.

Prokhorova, I., Altman, R. B., Duumagulov, M., Shrestha, J. P., Urzhumtsev, A., Ferguson, A., Chang, C. T., Yusupov, M., BLANCHARD, S. C. \& Yusupova, G. (2017). Aminoglycoside interactions and impacts on the eukaryotic ribosome. Proceedings of the National Academy of Sciences of the United States of America 114(51), E10899-E10908.

Rabea, S. M., Baradaran-Heravi, A., Balgi, A. D., Krause, A., Hosseini Farahabadi, S., Roberge, M. \& GRIERSON, D. S. (2019). 2-aminothiazole-4-carboxamides enhance readthrough of premature termination codons by aminoglycosides. ACS Medicinal Chemistry Letters 10(5), 726-731.

RAJON, E. \& MASEL, J. (2011). Evolution of molecular error rates and the consequences for evolvability. Proceedings of the National Academy of Sciences of the United States of America 108(3), 1082-1087.

REN, G., ZHAO, Y. P., YANG, L. \& FU, C. X. (2008). Anti-proliferative effect of clitocine from the mushroom leucopaxillus giganteus on human cervical cancer hela cells by inducing apoptosis. Cancer Letters 262(2), 190-200.

Roy, B., Friesen, W. J., Tomizawa, Y., Leszyk, J. D., Zhuo, J., Johnson, B., DakKa, J., Trotta, C. R., Xue, X., Mutyam, V., Keeling, K. M., Mobley, J. A., Rowe, S. M., BedWell, D. M., WelCh, E. M., et al. (2016). Ataluren stimulates ribosomal selection of near-cognate trnas to promote nonsense suppression. Proceedings of the National Academy of Sciences of the United States of America 113(44), 12508-12513.

ROY, B., LESZYK, J. D., MANGUS, D. A. \& JACOBSON, A. (2015). Nonsense suppression by near-cognate trnas employs alternative base pairing at codon positions 1 and 3. Proceedings of the National Academy of Sciences of the United States of America 112(10), 3038-3043.

SAlas-MARCO, J. \& BeDWELL, D. M. (2005). Discrimination between defects in elongation fidelity and termination efficiency provides mechanistic insights into translational readthrough. Journal of Molecular Biology 348(4), 801-815.

SChUeren, F., Lingner, T., GeORGe, R., HofHUis, J., DiCKel, C., GARTNeR, J. \& ThOMS, S. (2014). Peroxisomal lactate dehydrogenase is generated by translational readthrough in mammals. Elife $\mathbf{3}$, e03640.

Sermet-Gaudelus, I., Boeck, K. D., CasimiR, G. J., Vermeulen, F., Leal, T., Mogenet, A., Roussel, D., Fritsch, J., Hanssens, L., HiRAwat, S., Miller, N. L., Constantine, S., Reha, A., Ajayl, T., Elfring, G. L., et al. (2010). Ataluren (ptc124) induces cystic fibrosis transmembrane conductance regulator protein expression and activity in children with nonsense mutation cystic fibrosis. American Journal of Respiratory and Critical Care Medicine 182(10), 1262-1272.

Sermet-Gaudelus, I., Renouil, M., Fajac, A., Bidou, L., Parbaille, B., Pierrot, S., Davy, N., Bismuth, E., ReINERT, P., LENOIR, G., LESURE, J. F., ROUSSET, J. P. \& EdELMAN, A. (2007). In vitro prediction of stop-codon suppression by intravenous gentamicin in patients with cystic fibrosis: A pilot study. BMC Medicine 5, 5.

ShARMA, J., KeELING, K. M. \& Rowe, S. M. (2020). Pharmacological approaches for targeting cystic fibrosis nonsense mutations. European Journal of Medicinal Chemistry 200, 112436.

Shulman, E., Belakhov, V., Wel, G., Kendall, A., Meyron-Holtz, E. G., Ben-Shachar, D., Schacht, J. \& BAASOV, T. (2014). Designer aminoglycosides that selectively inhibit cytoplasmic rather than mitochondrial ribosomes show decreased ototoxicity: A strategy for the treatment of genetic diseases. The Journal of Biological Chemistry 289(4), 2318-2330. 
Singh, A., Manjunath, L. E., Kundu, P., Sahoo, S., Das, A., Suma, H. R., Fox, P. L. \& Eswarappa, S. M. (2019). Let-7a-regulated translational readthrough of mammalian ago1 generates a microrna pathway inhibitor. EMBO Journal 38(16), e100727.

SINGH, A., URSIC, D. \& DAVIES, J. (1979). Phenotypic suppression and misreading saccharomyces cerevisiae. Nature 277(5692), 146-148.

SkUzeSkI, J. M., Nichols, L. M., Gesteland, R. F. \& AtKINS, J. F. (1991). The signal for a leaky uag stop codon in several plant viruses includes the two downstream codons. Journal of Molecular Biology 218(2), 365-373.

SogaARd, T. M., JAKobSEN, C. G. \& JusteSEN, J. (1999). A sensitive assay of translational fidelity (readthrough and termination) in eukaryotic cells. Biochemistry (Mosc) 64(12), 1408-1417.

Song, H., Mugnier, P., Das, A. K., WebB, H. M., Evans, D. R., Tuite, M. F., Hemmings, B. A. \& Barford, D. (2000). The crystal structure of human eukaryotic release factor erf1--mechanism of stop codon recognition and peptidyl-trna hydrolysis. Cell 100(3), 311-321.

Sun, J., Yeung, C. A., Co, N. N., TSANG, T. Y., YAu, E., LuO, K., Wu, P., WA, J. C., Fung, K. P., KwOK, T. T. \& LIU, F. (2012). Clitocine reversal of p-glycoprotein associated multi-drug resistance through downregulation of transcription factor nf-kappab in r-hepg2 cell line. PLoS One 7(8), e40720.

SWAN, S. K. (1997). Aminoglycoside nephrotoxicity. Seminars in Nephrology 17(1), 27-33.

Taguchi, A., Hamada, K., Kotake, M., Shiozuka, M., Nakaminami, H., Pillaiyar, T., Takayama, K., YakushiJI, F., NOGUCHI, N., USUI, T., MATSUdA, R. \& HAYASHI, Y. (2014). Discovery of natural products possessing selective eukaryotic readthrough activity: 3-epi-deoxynegamycin and its leucine adduct. ChemMedChem 9(10), 2233-2237.

TAte, W. P. \& MANnering, S. A. (1996). Three, four or more: The translational stop signal at length. Molecular Microbiology 21(2), 213-219.

Temple, G. F., DozY, A. M., RoY, K. L. \& KAN, Y. W. (1982). Construction of a functional human suppressor trna gene: An approach to gene therapy for beta-thalassaemia. Nature 296(5857), 537-540.

Trzaska, C., Amand, S., Bailly, C., leroy, C., Marchand, V., Duvernois-Berthet, E., Saliou, J. M., Benhabiles, H., Werkmeister, E., Chassat, T., Guilbert, R., Hannebique, D., Mouray, A., Copin, M. C., Moreau, P. A., et al. (2020). 2,6-diaminopurine as a highly potent corrector of uga nonsense mutations. Nature Communications 11(1), 1509.

Tutone, M., Pibiri, I., Lentini, L., PACE, A. \& Almerico, A. M. (2019). Deciphering the nonsense readthrough mechanism of action of ataluren: An in silico compared study. ACS Medicinal Chemistry Letters 10(4), 522-527.

tutone, M., Pibiri, I., Perriera, R., Campofelice, A., Culletta, G., Melfi, R., Pace, A., Almerico, A. M. \& LENTINI, L. (2020). Pharmacophore-based design of new chemical scaffolds as translational readthrough-inducing drugs (trids). ACS Medicinal Chemistry Letters 11(5), 747-753.

Urakov, V. N., Valouev, I. A., LeWitin, E. I., Paushkin, S. V., Kosorukov, V. S., Kushnirov, V. V., Smirnov, V. N. \& TER-AVANESYAN, M. D. (2001). Itt1p, a novel protein inhibiting translation termination in saccharomyces cerevisiae. BMC Molecular Biology 2, 9.

Wagner, K. R., Hamed, S., Hadley, D. W., Gropman, A. L., Burstein, A. H., Escolar, D. M., Hoffman, E. P. \& FISCHBECK, K. H. (2001). Gentamicin treatment of duchenne and becker muscular dystrophy due to nonsense mutations. Annals of Neurology 49(6), 706-711.

Wang, D., Belakhov, V., Kandasamy, J., BaAsov, T., LI, S. C., LI, Y. T., BedWell, D. M. \& Keeling, K. M. (2012). The designer aminoglycoside nb84 significantly reduces glycosaminoglycan accumulation associated with mps $\mathrm{i}-\mathrm{h}$ in the idua-w392x mouse. Molecular Genetics and Metabolism 105(1), 116-125.

WANG, W., CZAPLINSKI, K., RAO, Y. \& PELTZ, S. W. (2001). The role of upf proteins in modulating the translation read-through of nonsense-containing transcripts. EMBO Journal 20(4), 880-890.

WANGEN, J. R. \& GREEN, R. (2020). Stop codon context influences genome-wide stimulation of termination codon readthrough by aminoglycosides. Elife 9, e52611. 
Welch, E. M., Barton, E. R., Zhuo, J., Tomizawa, Y., Friesen, W. J., Trifillis, P., Paushkin, S., Patel, M., Trotta, C. R., HWANG, S., Wilde, R. G., KarP, G., TAKAsugi, J., Chen, G., JONES, S., et al. (2007). Ptc124 targets genetic disorders caused by nonsense mutations. Nature 447(7140), 87-91.

Wilde, R. G., Kennedy, P. D., Almstead, N. G., Welch, E. M., Takasugl, J. J. \& Friesen, W. J. (2007). Nucleoside compounds and their use for treating cancer and diseaes associated with somatic mutations. In USPTO (Ed.), vol. 7291603B2 (ed. U. S. Patent). PTC Therapeutics, Inc, USA.

Wilhelm, J. M., JeSSOP, J. J. \& PETTITT, S. E. (1978). Aminoglycoside antibiotics and eukaryotic protein synthesis: Stimulation of errors in the translation of natural messengers in extracts of cultured human cells. Biochemistry 17(7), 1149-1153.

WiLls, N. M., GestelAND, R. F. \& ATKINS, J. F. (1991). Evidence that a downstream pseudoknot is required for translational read-through of the moloney murine leukemia virus gag stop codon. Proceedings of the National Academy of Sciences of the United States of America 88(16), 6991-6995.

Wittenstein, A., Caspi, M., David, Y., Shorer, Y., Nadar-Ponniah, P. T. \& Rosin-Arbesfeld, R. (2019). Serum starvation enhances nonsense mutation readthrough. Journal of Molecular Medicine (Berl) 97(12), 1695-1710.

WU, G., HUANG, C. \& YU, Y. T. (2015). Pseudouridine in mrna: Incorporation, detection, and recoding. Methods in Enzymology 560, 187-217.

Wu, W. J., Sha, S. H., Mclaren, J. D., KaWAmoto, K., Raphael, Y. \& Schacht, J. (2001). Aminoglycoside ototoxicity in adult cba, c57bl and balb mice and the sprague-dawley rat. Hearing Research 158(1-2), 165-178.

Xue, X., Mutyam, V., Tang, L., Biswas, S., Du, M., Jackson, L. A., Dal, Y., Belakhov, V., ShaleV, M., Chen, F., SCHACHT, J., R, J. B., BAASOV, T., HONG, J., BEDWELL, D. M., et al. (2014). Synthetic aminoglycosides efficiently suppress cystic fibrosis transmembrane conductance regulator nonsense mutations and are enhanced by ivacaftor. American Journal of Respiratory Cell and Molecular Biology 50(4), 805-816.

Xue, X., Mutyam, V., Thakerar, A., Mobley, J., Bridges, R. J., Rowe, S. M., Keeling, K. M. \& Bedwell, D. M. (2017). Identification of the amino acids inserted during suppression of cftr nonsense mutations and determination of their functional consequences. Human Molecular Genetics 26(16), 3116-3129.

Yamaguchi, Y., hayashi, A., CAmpagnoni, C. W., Kimura, A., InUzUKA, T. \& BABA, H. (2012). L-mpz, a novel isoform of myelin $\mathrm{p} 0$, is produced by stop codon readthrough. The Journal of Biological Chemistry 287(21), 17765-17776.

Yesmin, F., Bhuiyan, R. H., OHMi, Y., OhKaWA, Y., TaJima, O., OKaJima, T. \& Furukawa, K. (2020). Aminoglycosides are efficient reagents to induce readthrough of premature termination codon in mutant b4galnt1 genes found in families of hereditary spastic paraplegia. The Journal of Biochemistry 168(2), 103-112.

Zingman, L. V., Park, S., Olson, T. M., Alekseev, A. E. \& Terzic, A. (2007). Aminoglycoside-induced translational read-through in disease: Overcoming nonsense mutations by pharmacogenetic therapy. Clinical Pharmacology \& Therapeutics 81(1), 99-103.

Figure Legends

Fig. 1. Comparison of translation termination and stop codon readthrough mechanisms. (A)

Translation termination. When the ribosome reaches a stop codon, in most cases the

translation termination complex is recruited. When the A site of the ribosome covers a stop 
codon, eRF3 and ABCE1 interact with the ribosome. ABCE1 recruits the Dbp5/DDX19-eRF1 complex, likely with the help of PABPC1. Dbp5/DDX19 then hydrolyses ATP to ADP, promoting its own departure. The energy supplied by eRF3-driven GTP hydrolysis favours a change in the conformational structure of eRF1, with subsequent dissociation of the synthesised peptide. ABCE1-driven ATP hydrolysis supplies energy for the release of the ribosome, which is then recycled. (B) Stop codon readthrough. At a very low rate or under certain conditions (drugs, eIF3, regulatory elements), a near-cognate tRNA, rather than the translation termination complex, is recruited when the ribosome reaches a stop codon. The elongation factor EF-Tu allows polymerization of the peptide, with GTP hydrolysis leading to continuation of translation to the next stop codon. ABCE1, ATP-binding cassette sub-family E member 1; DDX19, DEAD-box helicase 19B; EF-Tu, elongation factor thermo unstable; eIF3, eukaryotic initiation factor 3; eRF, eukaryotic release factor; GGQ, glycine-glycineglutamine motif; mRNA, messenger RNA; PABP, polyA-binding protein; tRNA, transfer RNA.

Fig. 2. Different types of stop codon readthrough. (A) Non-programmed translational readthrough. This type of readthrough occurs at a basal level without any regulatory elements and without the presence of readthrough molecules. This readthrough happens at premature termination codons (PTCs) and physiological stop codons at a very low rate. (B) Programmed translational readthrough. Some mRNAs are subject to readthrough of the physiological stop codon, due to the presence of regulatory elements. This type of readthrough is more efficient than that shown in A. (C) Induced translational readthrough. The presence of molecules (aminoglycosides or non-aminoglycosides) promotes activation of readthrough. This type of readthrough is more efficient than that shown in A. DDX19, DEAD-box helicase 19B; eRF, 
eukaryotic release factor; GGQ, glycine-glycine-glutamine motif; mRNA, messenger RNA;

1189 PABP, polyA-binding protein; tRNA, transfer RNA; UTR, untranslated region.

Fig. 3. Strategies used to screen molecules for readthrough-promoting activity. (A) A premature termination codon (PTC) is introduced into a cDNA encoding an enzyme or a fluorescent protein. Measurement of the enzymatic activity or fluorescence related to this protein will indicate that readthrough has occurred. (B) Use of two cDNAs encoding an enzymatic activity or a fluorescence separated by a stop codon. The product of the first cDNA is used to normalize the signal. Measurement of the product of the second cDNA will indicate that readthrough has occurred. (C) Screening system with an intron introduced into a cDNA to promote a splicing event. The PTC is introduced more than 55 nucleotides upstream of the intronic sequence to activate nonsense-mediated mRNA decay (NMD) of the corresponding mRNA.

Table 1. Aminoglycoside molecules with known readthrough activity.

Table 2. Non-aminoglycoside molecules with known readthrough activity.

Table 3. Readthrough potentiator molecules. 